Primljen / Received: 22.11.2013. Ispravljen / Corrected: 13.3.2014.

Prihvaćen / Accepted: 28.4.2014. Dostupno online / Available online: 10.5.2014.

\section{Water mass oscillations in a generic surge chamber}

Author:

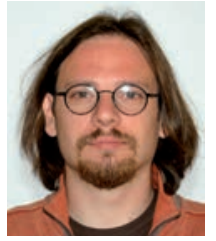

Assist.Prof. Vanja Travaš, PhD. CE University of Rijeka Faculty of Civil Engineering vanja.travas@uniri.hr

\section{Vanja Travaš \\ Water mass oscillations in a generic surge chamber}

Numerical models are currently most often used to simulate water mass oscillations inside the system formed of the reservoir, pressure tunnel, and surge chamber. At the same time, regardless of the method used for discretisation of governing equations, the numerical models are most often developed under assumption that the surge chamber is characterized by the constant and circular cross section. To omit this restrictive assumption, a numerical algorithm is proposed to enable analysis of water level oscillations in a generic surge chamber.

Key words:

hydraulic transients, finite difference method, unsteady flow, water mass oscillations, surge chamber

Prethodno priopćenje

\section{Vanja Travaš}

\section{Oscilacije vodnih masa u vodnoj komori generičkog oblika}

Numerički modeli zasad se najčešće koriste u svrhu prognoziranja oscilacija vodnih masa u sustavu akumulacija - dovodni tunel - vodna komora. Pritom, neovisno o usvojenoj metodi diskretizacije vladajućih jednadžbi, najčešće se susreće da su ti modeli razvijeni pod pretpostavkom da je vodna komora okarakterizirana kružnim i konstantnim poprečnim presjekom. Da bi se zaobišla ta ograničavajuća pretpostavka, predložen je numerički algoritam kojim se mogu analizirati oscilacije razine vode u vodnoj komori općenitog oblika.

Ključne riječi:

hidraulički tranzijenti, metoda konačnih razlika, nestacionarno strujanje, oscilacije vodnih masa, vodna komora

Vorherige Mitteilung

\section{Vanja Travaš}

\section{Schwingungen von Wassermassen in Wasserkammern generischer Form}

Die Anwendung numerischer Modelle ist derzeit weit verbreitet zur Simulation der Schwingungen von Wassermassen innerhalb des Systems Akkumulation Versorgungstunnel - Wasserkammer. Gleichzeitig werden die numerischen Modelle oft, unabhängig von der angewandten Methode zur Diskretisierung der entsprechenden Gleichungen, unter der Annahme entwickelt, dass die Wasserkammer durch einen konstanten, kreisförmigen Querschnitt charakterisiert werden kann. Um diese einschränkende Voraussetzung zu umgehen, ist ein numerischer Algorithmus vorgeschlagen, der die Analyse von Schwingungen des Wasserstandes in Wasserkammern generischer Form ermöglicht.

Schlüsselwörter:

hydraulische Transienten, Finite-Differenzen-Methode, nichtstationäre Strömung, Schwingung von

Wassermassen, Wasserkammer 


\section{Introduction}

Surge chambers can be classified into the group of essential functional elements of high-head hydropower plants. In typical high-head hydropower plants (Figure 1), the role of surge chambers is manifested in the time of hydraulic transients i.e. in the time period within which the passage is operated from one stationary state into another stationary state defined by different flow within the system. The need to manipulate the flow rate in the system arises from the momentary electricity generation requirement and, in that respect, the action is taken via inlet wheel blades or rotor blades at the entrance to the power house. Taking the above into account, two basic flow manipulation types can be differentiated: (i) reduction of momentary flow to a value set in advance and (ii) increase of flow to a value set in advance. In these situations, two extreme cases may be distinguished: (i) turning on the hydropower plant by bringing it from an inactive state into the state of maximum operation at installed flow, and (ii) turning off the hydropower plant by disengaging it from the operation state defined with an installed flow rate.

The above two scenarios for turning on and turning off the hydropower plant cause the least favourable conditions of flow, in which the full significance of surge chambers can be recognised. At that, in addition to the obvious need for having adequate dimensions, the role of a surge chamber is fully fulfilled by an appropriate selection of its position with respect to other functional elements of hydropower plants. In fact, it has to be located at the end of the headrace tunnel, i.e. at the contact between the headrace tunnel and the penstock (Figure 1)

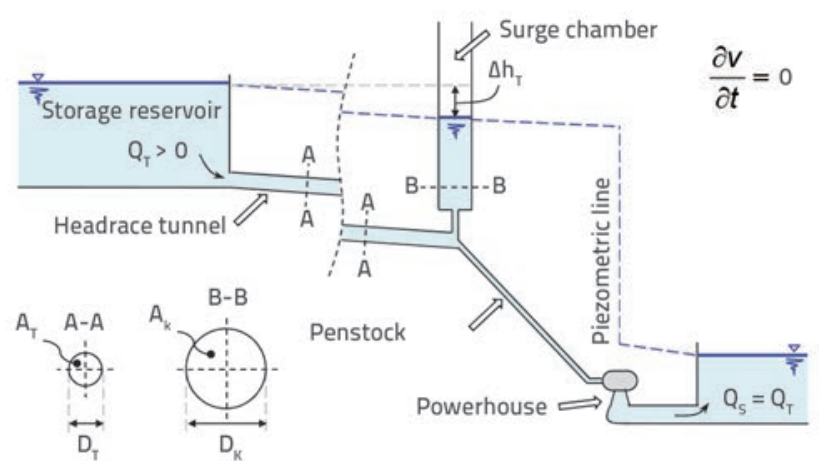

Figure 1. Position of functional elements within a high-head hydropower plant

In relation to geometric, cinematic an dynamic flow properties defined in advance, one of the tasks of the hydraulic analysis is to anticipate the resulting time-dependent change of water level in the surge chamber. The result of this analysis is inter alia used in the surge chamber dimensioning process, during which the geometry of the chamber has to be defined in such a way to avoid water spilling (overflow) during maximum oscillations, and the suction of air into the headrace tunnel and penstock during minimum oscillations.
Over the past several decades, these analyses have most often been conducted using numerical methods through which the resulting system of governing differential equations has been solved approximately, for the specified initial and boundary conditions. The problem of finding approximate solutions for this system can be approached in several ways. In this respect, an emphasis may be placed on the recent use of the finite element method [1], but also on the frequently used finite difference method [2,3]. At that, the point that can most often be registered as a common basis in these different approaches, both based on the above literature and according to other authors [4-8], is the assumption that water level oscillations take place in the surge chamber of a constant and circular cross section, i.e. in a cylindrical water chamber. In order to exclude this restrictive assumption and generalize computation for the prognosis of oscillations in surge chambers of general form, the author proposes a numerical technique that can be used, due to its simplicity, regardless of the methodology applied for finding numerical solutions to governing equation systems.

\section{Theoretical oscillation model}

All analyses considered in the following text are made under assumption that the water mass in the high-pressure system forms a continuous whole, i.e. that conditions justifying explanation of flow through the continuum hypothesis prism are valid [3]. In fact, although this assumption is most often accepted as valid in advance for the flow of liquids through pressure systems, and although it generally does not require any special emphasis, in the circumstances under study there are cases in which the continuum assumption is not justified. The circumstances in which the use of continuum hypothesis is not justified may occur in case of a sudden opening of the gate when, due to a relatively sudden increase in flow rate, the water pressure falls down to the water vapour pressure. If preconditions for the above mentioned are ensured, they will be manifested by the interruption of the water column [9] and, in order to model such occurrences, the basic equation system must be extended by adding appropriate constitutive relations that introduce the change of phase, i.e. the change of the aggregate state of water [10].

\subsection{Dynamic equation}

If we temporarily neglect the influence of viscosity, Euler's equation (3) can be used in order to define Bernoulli equation for unsteady flow. With subsequent inclusion of the influence of friction, the obtained equation defines - via inclusion of the Darcy-Weisbach equation - the energy equivalence between the distant particles of water that are in unsteady flow at the same streamline within the hydropower plant. The following can be written for the water particle on the surface of the storage reservoir and for the water particle on the surface of water at the water chamber: 
$h_{A}=h_{K}+\left.\Delta h_{T}\right|_{A} ^{K}+\frac{1}{g} \int_{A}^{K} \frac{\partial v_{T}}{\partial t} d x$,

where: $h_{A}$ is the water level in the storage reservoir (measured from a reference level defined in advance), $h_{K}$ is the water level in the surge chamber (measured from the same plane), $\Delta h_{T}$ is the pressure loss on the way from the storage reservoir to the surge chamber (Figure 2), $g$ is the gravitational acceleration and $(x, t)$ is the flow rate in the headrace tunnel.

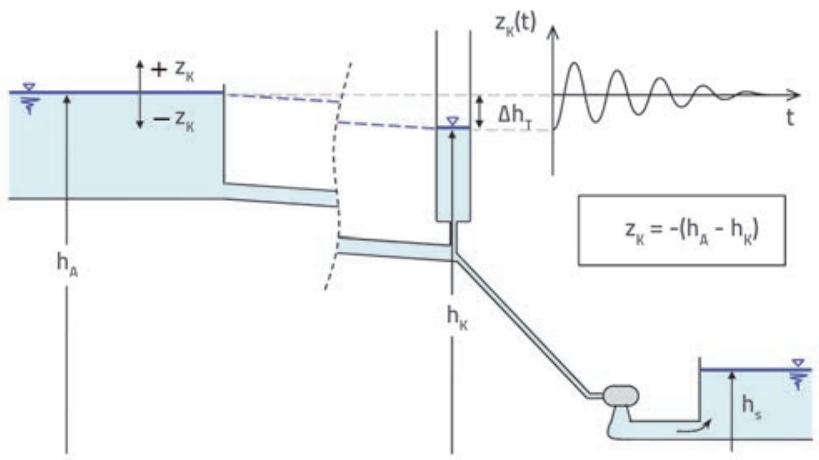

Figure 2. Relevant geometrical values for the storage reservoir headrace tunnel - surge chamber system

The last termof equation (1) is the integral value of the energy height needed to change the speed $v_{T}(x, t)$ in the differential segment $d x$ along the $x$ axis of the headrace tunnel. Assuming that there are no delays in speed change in the headrace tunnel, the member $\partial v_{T} / \partial t$ is not dependent on the chainage and the speed $v_{T}(x, t)$ becomes the function of the only one argument $v_{T}(t)$. In the light of the above, and by quantifying the member $\Delta h_{T}$ via DarcyWeisbach equation [3, 4], equation (1) can be written as follows:

$h_{A}=h_{K}+\lambda \frac{L_{T}}{D_{T}} \frac{v_{T}^{2}}{2 g}+\frac{L_{T}}{g} \frac{d v_{T}}{d t}$

where: $L_{T}$ is the headrace tunnel length, $D_{T}$ is the headrace tunnel diameter and $\lambda$ is the Darcy's friction factor. Assuming that the cross section of the headrace tunnel $D_{T}$ is constant, the speed $v_{T}(t)$ in equation (1) can be expressed via the realized flow $Q_{T}$ and we obtain

$h_{A}=h_{K}+\lambda \frac{L_{T}}{D_{T}} \frac{Q_{T}^{2}}{2 g A_{T}^{2}}+\frac{L_{T}}{g A_{T}} \frac{d Q_{T}}{d t}$,

or

$\frac{d Q_{T}}{d t}=\frac{g A_{T}}{L}\left(h_{A}-h_{K}\right)-\frac{2 \lambda}{\grave{A} D_{T}^{3}} Q_{T}\left|Q_{T}\right|$,

where the absolute value on the RHSis introduced in order to preserve the correct orientation of the friction force. Considering the significant difference between the water volume in the storage reservoir and the water volume in the hydropower plant, it is quite logical to introduce the assumption that the water level $h_{A}$ can be considered constant during the oscillation time. In fact, this ratio can be used as an argument for neglecting the increase of level $h_{A}$ over time when oscillations cause some water to overflow from the headrace tunnel into the storage reservoir. In the light of the above, the difference $\left(h_{A}-h_{K}(t)\right)$ in equation (4) can be substituted with the negative value ${ }_{k}(t)$ that is introduced as a measure of deviation of water level in the surge chamber from the water level in the storage reservoir (Figure 2). At that, in order to define local losses at the entrance to the surge chamber, which are introduced on purpose in order to regulate the influence of dissipation forces and hence the oscillation time $[3,4]$, the piezometric level in the surge changer must be reduced for the local losses realized. In this way equation (4) can be written as follows:

$$
\frac{d Q_{T}}{d t}=\frac{g A_{T}}{L}\left(-z_{K}-\xi_{P} \frac{Q_{K}\left|Q_{K}\right|}{2 g A_{P}^{2}}\right)-\frac{2 \lambda}{\Pi D_{T}^{3}} Q_{T}\left|Q_{T}\right|,
$$

where: $\xi_{p}$ is the coefficient of local losses at the entrance to the surge chamber, ${ }_{k}(t)$ is the flow in the surge chamber, and $A_{p}$ is the flow area at the entrance to the water chamber. This purposeful induction of local losses can be conducted in various ways [11] and, at that, an appropriate attention should be paid that the defined local losses are not reflected on: (i) regulation of turbine operation due to a more difficult surge chamber emptying during the powering-on of the hydropower plant and (ii) transmission of hydraulic impact to the headrace tunnel due to a more difficult surge-chamber filling during the powering-off of the hydropower plant [4].

\subsection{Continuity equation}

From the numerical modelling perspective, the simplest case of water mass oscillation is the one in which the surge chamber is characterized by the constant cross section $A_{K}$ (e.g. cylindrical surge chamber). In such circumstances, the exchange of water mass between the headrace tunnel, surge chamber and penstock can be expressed by continuity equation as follows:

$A_{K} \frac{d z_{K}}{d t}=\left(Q_{T}-Q_{S}\right)$,

where $Q_{S}$ is the penstock flow rate that is harmonized with the flow rate at turbines in the power houses, in accordance with the rigid column theory $[12,13]$. In the time period in which the relation $Q_{S}>Q_{p}$ is valid, the $z_{K}$ level falls proportionally with the difference in flow rate until the steady state of flow is achieved, and vice versa. At that, surge chambers of constant cross section $A_{k}$ are relatively seldom applied in practice and are most often used to prepare preliminary analyses i.e. in order to define geometry with which the dimensioning procedure will be initiated. In case of surge chambers of general form, the continuity equation assumes the following form:

$A_{K}\left(z_{K}\right) \frac{d z_{K}}{d t}=\left(Q_{T}-Q_{S}\right)$,

where the cross-sectional area of the surge chamber is now dependent on the water level in the chamber $A_{k}\left(z_{k}\right)$. Although 
the function $A_{k}\left(z_{k}\right)$ is known in advance, the solution of equation (7) is not trivial as in the case of equation (6) because the raising or lowering of the level $d z_{k}$ over time $d t$ will be dependent on the momentary level of water in the surge chamber.

\section{Integration of continuity equation}

The numerical modelling of water level oscillation in surge chambers of generic form will require an adequate integration of continuity equation (7). The following two methods are proposed for this purpose:

- direct or exact and

- incremental or approximate.

At that, in order to follow the time-dependent changeability of interesting variables, all relevant values dependent on past time will be associated below with the corresponding time situations by means of the discrete time coordinate $n$. The time period between two neighbouring coordinates $n$ and $n+1$ is defined by the time increment $\Delta t$.

\subsection{Direct integration}

To solve equation (7), the separation of variables is conducted

$A_{K}\left(z_{K}\right) d z_{K}=\left(Q_{T}-Q_{S}\right) d t$

The RHS of equation (8) is integrated over the time interval $\Delta t$, defined with the starting time $t^{(n)}$ and the ending time $t^{(n+1)}$. The LHS of equation (8) is integrated between the limits defined by the initial water level $z_{K}^{(n)}$ at $t^{(n)}$ and the unknown water level $z_{K}^{(n+1)}$ at $t^{(n+1)}$. Accordingly, the following may be written:

$\int_{z_{K}^{(n)}}^{z_{K}^{(n+1)}} A_{K}\left(z_{K}\right) d z_{K}=\int_{t^{(n)}}^{t^{(n+1)}}\left(Q_{T}-Q_{S}\right) d t$

Assuming that the time increment $\Delta t$ is sufficiently small, so that the flows $Q_{T}$ and $Q_{S}$ can be considered constant within such increment, the right side of equation (9) will define the water volume $\Delta V$ that either fills or empties the surge chamber in a time increment $\Delta t(10)$.

$$
\Delta V=\left(Q_{T}^{(n)}-Q_{S}^{(n)}\right) \Delta t
$$

For the flow difference known in advance $\left(Q_{T}^{(n)}-Q_{S}^{(n)}\right)$ and the surge chamber geometry $A_{k}\left(z_{k}\right)$, equations (9) and (10) define the equality:

$\Delta V=\int_{z_{K}^{(n)}}^{z_{K}^{(n+1)}} A_{K}\left(z_{K}\right) d z_{K}$,

in which the top boundary of the integral on the RHS is the unknown water level $z_{k}^{(n+1)}$. In order to quantify this value, the reference should be made to the Newton-Leibniz formula that defines the basic relationship between the differential and integral calculus as follows: $\int_{a}^{b} f(x) d x=\left.F(x)\right|_{a} ^{b}=F(b)-F(a)$,

in which $F(x)$ is the primitive function of the function $f(x)$ with the property $d F / d x=f(x)$. As the function $A_{k}\left(z_{k}\right)$ is known in advance, so that its derivation is also known, the relation (12) can be used to write equation (11) as follows

$\Delta V=A_{p r}\left(z_{K}^{(n+1)}\right)-A_{p r}\left(z_{K}^{(n)}\right)$,

where the function $A_{p r}\left(z_{k}\right)$ is the primitive function of the function $A_{k}\left(z_{k}\right)$ defined with $d A_{p r} / d z_{k}=A_{k}\left(z_{k}\right)$. The terms on the RHS of equation (13) are in this way defined with integration of the function $A_{k}\left(z_{k}\right)$. At that, the numerical value of the function $A_{p r}\left(z_{k}\right)$ will be assumed only by the second term on the RHS, as the level of $z_{k}^{(n)}$ is known for this term, while the first term of the RHS will be expressed via an unknown value $z_{K}^{(n+1)}$. As the volume of water $\Delta V$ is known (10), equation (13) can now be solved according for the unknown level $z_{K}^{(n+1)}$ and, in this way, the change in water level reflecting the change of water volume $\Delta V$ in the surge chamber of irregular shape would be determined.

Although this method can be used to establish a direct relationship between the change in water volume with the change in water volume in surge chamber, the computational implementation of this method is less attractive as it requires a symbolic integration of the function $A_{k}\left(z_{k}\right)$. It should also be noted that surge chambers with local change in geometry are most often applied for practical purposes, and that this change of geometry occurs in places where expanded segments are realized and is aimed at regulating water level oscillations occurring during the powering on and off of the hydropower plant (e.g. gallery type surge chambers). For that reason, the function $A_{k}\left(z_{k}\right)$ is most often characterized by a local interruption, which makes the computation of this method more difficult as it requires symbolic integration of the improper integral of the second order. All this justifies development of the numerical scheme that is described below.

\subsection{Incremental integration}

The incremental method, based on the idea of replacing the integral on the RHS of equation (11) with the final sum of all related terms, is introduced in order to avoid difficulties related to the direct computer integration of equation (7). In other words, in every time increment $\Delta t$, the volume of water $\Delta V_{K}=\left(Q_{T}-Q_{S}\right) \Delta t_{n}$ that is filling or emptying the surge chamber is divided into an equal number of segments $\Delta V_{K^{\prime}}$ After that, each segment $\Delta V_{K}$ is introduced into or discharged from the surge chamber through a series of computer steps, and the corresponding incremental changes in water level $\pm \Delta z_{K}$ are defined under assumption that every volume $\Delta V_{K}$ either fills or empties the space of the surge chamber of constant cross section $A_{K^{\prime}}$ In this case, the incremental change $\pm \Delta z_{K}$ can trivially be determined in form of $\Delta V_{K} / A_{K}$. At that, in 
order to take into account any change in the surge chamber geometry, the cross sectional area $A_{K}$ is updated in every computation step and is accepted as being equal to the cross section of the defined surge chamber $A_{k}\left(z_{k}\right)$ at the attained water level $z_{k}$. The computation accuracy increases with the number of incremental contributions $\Delta V_{k}$ and, if the number of incremental contributions $\Delta V_{k}$ strives toward infinity, the described is defined by the integral from equation (11).

The described procedure will be defined below in form of an algorithm. First of all, it should be observed that, in the mentioned interpretation, the progressive filling or emptying of the chamber should not be understood as a physical occurrence but rather as a computation principle. In fact, the successive superposition of incremental changes $\pm \Delta z_{k}$ does not occur during the progress of oscillations, but rather in a single moment, i.e. at the beginning of the time increment $\Delta t$. For that reason, these computation steps must be understood as increments of a pseudo time or fictitious time. The terminology is appropriate as, other than the above mentioned, the described procedure does not include the manifestation of inertia forces, and hence also the real time.

For a time increment $\Delta t$, the number of fictitious time steps $n \Delta t_{f}$ within which incremental contributions $\pm \Delta z_{k^{\prime}}$ will be superposed, will define the increment of volume that either fills or empties the surge chamber

$\Delta \mathrm{V}_{\mathrm{K}}=\frac{\left(\mathrm{Q}_{\mathrm{T}}-\mathrm{Q}_{\mathrm{S}}\right) \Delta \mathrm{t}}{\mathrm{n} \Delta \mathrm{t}_{\mathrm{T}}}$.

If we take that $k$ is the number of a fictitious time step, then the incremental change of level $\pm \Delta z_{K}$ for the first step $k=1$ will amount to

$\Delta z_{K}\left({ }^{k} z_{K}\right)=\frac{\Delta V_{K}}{A_{k}\left({ }^{k} z_{K}\right)}$,

where ${ }^{k} Z_{K}$ stands for the known water level in the chamber, i.e. for the water level at the beginning of the time step $\Delta t$ denoting the start of computation. In the next computation step $k+1$, the water level ${ }^{k+1} z_{k}$ will be defined with

${ }^{k+1} z_{K}={ }^{k} z_{K}+\Delta z_{K}\left({ }^{k} z_{K}\right)$.

This defines the cyclic computation principle in which every cycle ends with an update of the ordinal number of a calculation step

$k=k+1$

which is followed by the start of a new cycle in which equations (15) and (16) are solved. The procedure is repeated until the conditions $k=n \Delta t_{f}$ is met via equation (17). In other words, at the end of the time interval $\Delta t$, the water level in the surge chamber $z_{K}^{(n+1)}$ will be equal to the level ${ }^{k} z_{k}$ when $k=n \Delta t_{f}$

\section{Numerical algorithm}

The incremental integration of the continuity equation will be complemented with the dynamic equation in order to form a computation algorithm for the computational simulation of oscillation of water level in the surge chamber of general form. The direct integration of continuity equation (13) will not be considered because of the earlier mentioned difficulties.

\subsection{Definition of initial conditions}

Initial conditions define values of variables $z_{K}^{(n)}$ and $Q_{T}^{(n)}$ at the beginning of the first time step $\Delta t$ at the moment $n=1$. If a stationary state of flow in which $Q_{S}>0$ is to be defined with initial conditions, then in such a case a preliminary computation must be made. In this computation, the losses of height pressure $\Delta h_{T}$ (Figure 2 ) must be defined below the entrance to the surge chamber for a given flow geometry and flow rate $Q_{S^{*}}$. In fact, in stationary flow conditions, the surge chamber can be interpreted as a piezometer in which the water level $z_{K}^{(n)}$ corresponds to the height pressure $h_{A}-\Delta h_{T}$ at the end of the headrace tunnel. On the other hand, for the situation in which the hydropower plant does not operate, the initial conditions would be trivial as in such a case the flow rate $Q_{T}^{(n)}=0$ and there is no deviation $z_{K}^{(n)}$ form the water level in the storage reservoir $h_{A^{*}}$. Consequently, the computation of oscillations should start for the case of start-up of the hydropower plant (following the no-operation state of the plant) and, once the oscillations are fully damped, the calculated values $z_{K}$ and $Q_{T}$ shoud be adopted as initial conditions for the analysis of oscillations occurring at the turn-off of the hydropower plant.

\subsection{Definition of boundary condition}

The boundary condition defines the rate of change of flow area $A_{s}^{(n)}$ at turbines, and is specified as a function of the level of opening of the gate $\beta$ as defined by the relationship:

$\beta=\frac{A_{s}}{A_{S}^{(0)}}$,

where $A_{s}$ denotes the momentary flow area at the gate profile, while $A_{s}^{(0)}$ defines the flow area in case of an opened gate. The level of gate opening will influence the flow rate $Q_{S}$. In order to establish this functional dependence, we can assume that energy losses at the penstock section and in the power house can be neglected. In this case, the flow rate $Q_{S}$ in the gate profile can be calculated from the Torricelli's equation as follows

$Q_{S}=c_{p} \beta A_{S}^{(0)} \sqrt{2 g\left(\Delta h_{S}+z_{K}\right)}$,

where $c_{p}$ denotes the flow coefficient, and $\Delta h_{s}$ is the height difference between the water level in the storage reservoir $h_{A}$ and the water level at the exit from the machine hall $h_{S}$ in case when the hydropower plant is out of operation. It should be noted that, regardless of the specified gate closing or opening rate, the flow rate $Q_{S}$ will also change due to the time-related oscillation of water in the surge chamber. That is why the height pressure under the root (19) changes in accordance with the 
realized change of water level in the chamber. Depending on the specified rate of change of $\beta$, the same boundary condition can be used to simulate events of turning on the plant, and also the event of turning off the plant. In addition, the boundary condition enables modelling of the transition process through which the change from the specified stationary state to the second stationary state is operated (e.g. by increasing the number of turbines in the plant).

\subsection{Implementation of numerical algorithm}

The above presented method for the integration of continuity equation will be used below to form a computation algorithm for the computer-aided simulation of the transient state of flow. The computation algorithm begins through definition of the time increment $\Delta t$ by dividing the predicted period of oscillations $[2,3,4]$ into a greater number of increments. The number of time steps depends on the selection of time within which the oscillation process will be considered. Considering the nature of the analysis, appropriate initial conditions have to be defined by specifying variables $z_{K}^{(n)}, Q_{T}^{(n)}$ and $Q_{K}^{(n)}$ at the beginning of the first time step at the moment $n$. For the initial conditions specified, the numerical algorithm is used to define the transient state through which the flow rate in the power house is attained by the specified boundary condition. At that, the boundary condition is set as a function of change in time of the opening level of the gate (18). The function is set incrementally, i.e. the gate opening level is defined at the beginning of each time increment $n$ in form of

$$
\beta^{(n)}=\frac{A_{S}^{(n)}}{A_{S}^{(0)}} .
$$

As geometric characteristics of the pressure system, initial conditions, and boundary conditions are now defined, oscillations can be simulated by computer using the following set of equations. The order in which equations are presented follows the order in which equations are solved. First, the flow rate at turbines is defined for the current time step $n$ :

$$
Q_{S}^{(n)}=c_{p} \beta^{(n)} A_{S}^{(0)} \sqrt{2 g\left(\Delta h_{S}+z_{K}^{(n)}\right)}
$$

The difference between the known flow rate in the headrace tunnel $Q_{T}^{(n)}$ and the flow rate from equation (21) actually defines the flow rate $Q_{K}^{(n)}$ at which the surge chamber is filled or emptied in the time step $\Delta t$. To calculate the resulting change in water level, the water volume is defined as follows

$$
\Delta V_{K}^{(n)}=\frac{\left(Q_{T}^{(n)}-Q_{S}^{(n)}\right) \Delta t}{n \Delta t_{\text {fiktivno }}},
$$

Here $n \Delta t_{f}$ stands for the number of fictitious time steps in which cyclic changes in water level will be operated. The selection of the value $n \Delta t_{f}$ can greatly influence the results of water level oscillation in the irregularly shaped surge chambers, which is why it has to be adequately defined. In this respect, it should be noted that $n \Delta t_{f}$ may vary between the time steps. This fact enables the increase or reduction of $n \Delta t_{f}$ as required, depending on the water volume $\Delta V=\left(Q_{T}-Q_{S}\right) \Delta t$ by which the surge chamber is either filled or emptied in the time step $\Delta t$. Therefore, a greater number of steps $n \Delta t_{f}$ will be needed for greater values of the volume $\Delta V$. The possibility of successive change of $n \Delta t_{f}$ is in favour of the idea of defining, instead of this non-intuitive value, the water volume $\Delta V_{k}$ at which the surge chamber will progressively be either filled or emptied. In fact, the continuity equation (22) shows that the following can be deduced from the known water volume $\Delta V$

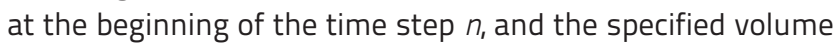
$\Delta V_{\dot{K}}: n \Delta t_{f}=\Delta V / \Delta V_{K^{\prime}}$ In this way, the problem of specifying a non-physical value is avoided by specifying the value $\Delta V_{K}$ which can geometrically be interpreted and put into a relative relationship with the volume of surge chamber.

The initialisation of computation is conducted by setting the counter of fictitious time steps $k$ to 1 , and by adopting the momentary water level $z_{K}^{(n)}$ as the starting water level in the chamber ${ }^{k} z_{K}^{(n+1))}$. The incremental change in water level $\pm \Delta z_{K}$ is defined according to equation

$\Delta z_{K}\left({ }^{k} z_{K}^{(n+1)}\right)=\frac{\Delta V_{K}^{(n)}}{A_{k}\left({ }^{k} z_{K}^{(n+1)}\right)}$,

and is used to correct the momentary water level by equation

${ }^{k+1} z_{K}^{(n+1)}={ }^{k} z_{K}^{(n+1)}+\Delta z_{K}\left({ }^{k} Z_{K}^{(n+1)}\right)$.

Before the procedure is repeated for the next fictitious time step, it must be updated

$k=k+1$

The procedure defined by equations (23), (24) and (25) is repeated in this order until the condition $k=n \Delta t_{f}$ is achieved. The result of this algorithm is the water level in surge chamber $z_{K}^{(n+1))}$ at the end of the time interval $\Delta t$. The achieved level defines the pressure gradient in between the ends of the headrace tunnel, which is why it is used in the dynamic equation for defining the flow rate in the headrace tunnel $Q_{T}^{(n+1)}$. At that, in addition to the pressure gradient formed, the flow rate in the headrace tunnel $v_{T}$ will also depend on resistance values occurring along the tunnel. In order to quantify the resistance values, the Reynolds number $\mathrm{Re}^{(n)}$ at the beginning of the time step $\Delta t$ is calculated below, using the relationship

$\operatorname{Re}^{(n)}=\frac{\rho v_{T}^{(n)} D_{T}}{\mu}$,

in which $\mu$ is the dynamic coefficient of viscosity, $\rho$ is the water density, and $v_{T}^{(n)}$ is the flow rate defined with $Q_{T}^{(n)} / A_{T}$ For turbulent flow, the Darcy's coefficient $\lambda$ can be defined with Colebrook equation [14] or with the explicit approximation of its results through equation [15] 
$\lambda^{(n)}=\left(-1.8 \log \left(\frac{6.9}{\operatorname{Re}^{(n)}}+\left(\frac{\varepsilon_{T} / D_{T}}{3.7}\right)^{1.11}\right)\right)^{-2}$,

in which $\varepsilon_{T}$ is the absolute operational roughness of the headrace tunnel walls. Due to the fact that the speed $v_{T}$ will change the direction of flow during oscillation of water masses in case the valve is closed, at some moment the flow in the headrace tunnel will shift from turbulent to laminar regime [16]. In such circumstances, the value $\lambda^{(n)}$ can be defined by the relationship $64 / \operatorname{Re}^{(n)}$. In addition to linear losses, the coefficient of local losses $\xi_{P}^{(n)}$ at the entrance to the surge chamber [17] is also defined below. At that, if the hydraulic diode [11] is used as the damper, the value of coefficient $\xi_{p}^{(n)}$ must be differentiated depending on the direction of flow. That is why the calculation starts with the flow $Q_{k}^{(n)}$ that either fills or empties the surge chamber:

$Q_{K}^{(n)}=Q_{T}^{(n)}-Q_{S}^{(n)}$,

which is followed by definition of the corresponding coefficient of local losses (29).

$$
\xi_{\mathrm{P}}^{(\mathrm{n})}=\left\{\begin{array}{lll}
\xi_{\text {input }} & \text { if } & \mathrm{Q}_{\mathrm{K}}^{(\mathrm{n})}>0 \\
\xi_{\text {output }} & \text { if } & \mathrm{Q}_{\mathrm{K}}^{(\mathrm{n})} \leq 0
\end{array}\right.
$$

The defined loss coefficients (27) and (29), and the realized water level $z_{K}^{(n+1)}$, are used to define the flow rate $Q_{T}^{(n+1)}$ at the end of the time step $\Delta t$. For that purpose, the left side of equation (5) can be approximated with the difference in advance [2], and thus the following explicit approximation of the flow rate $Q_{T}^{(n+1)}$ is obtained:

$Q_{T}^{(n+1)}=Q_{T}^{(n)}+\Delta t\left(\frac{g A_{T}}{L_{T}}\left(-\frac{z_{K}^{(n+1)}+z_{K}^{(n)}}{2}-\xi_{P}^{(n)} \frac{Q_{K}^{(n)}\left|Q_{K}^{(n)}\right|}{2 g A_{P}^{2}}\right)-\frac{2 \lambda^{(n)}}{\pi D_{T}^{3}} Q_{T}^{(n)}\left|Q_{T}^{(n)}\right|\right)$.

Each time stepndt ends by the counter update:

$n=n+1$

and the procedure defined in equations (21) through (31) is repeated until the stationary state of flow is achieved, i.e. until the difference between $z_{k}$ in two neighbouring time increments becomes smaller than the tolerance value defined in advance.

\section{Numerical example}

Gallery type surge chambers are nowadays most often used as a means to minimize undesirable effects of water level oscillation in surge tank on the operation of turbines, and to reduce the necessary tank height during oscillations caused by the powering-off of the plant. The manipulation of oscillations occurring in these states of operation is conducted in case of gallery type surge chambers by adequate dimensioning of two extensions. The role of the bottom extension, $D_{d}\left(z_{k}\right)$ in diameter, is to regulate oscillations caused during the start-up of the plant, while the top extension $D_{g}\left(z_{k}\right)$ is aimed at reducing the maximum water level in surge chamber in case of powering-off of the plant. Changes in cross section of the surge chamber are defined with the function $A_{k}\left(z_{k}\right)_{1}$, which is specified with regard to the water level in the storage reservoir.

A gallery type surge chamber will be used in the preparation of numerical examples. At that, the water chamber dimensioning procedure will be presented by means of a numerical example for predefined geometrical and kinematic properties of flow. For this purpose, the parametric analysis of oscillations will be conducted for the case of start-up of the hydropower plant, and this analysis will be followed by dimensioning of the top extension of the surge chamber so as to minimise the height of the surge chamber. The oscillation analysis protocol is defined in Figure 3.

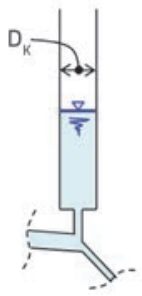

b)

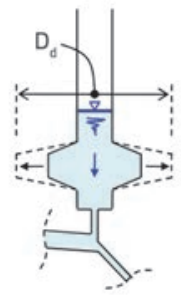

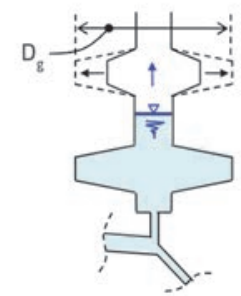

Figure 3. Surge chamber dimensioning protocol: a) definition of initial geometry by cylindrical surge chamber $D_{k}=4 \mathrm{~m}$ in diameter, b) gradual widening of the bottom part ( $D_{d}$ in diameter) for the regulation of oscillations $z_{k}$ occurring after the plant start-up, and c) gradual widening of the top part $\left(D_{g}\right.$ in diameter) for the regulation of oscillations $z_{k}$ occurring after the plant shut-down

The hydropower plant geometry is defined by the following values: headrace tunnel length $L_{T}=6000 \mathrm{~m}$, headrace tunnel diameter $D_{T}=3 \mathrm{~m}$, absolute roughness of the headrace tunnel $\varepsilon_{T}=3 \mathrm{~mm}$, diameter of flow area at turbines $D_{S}=0.6 \mathrm{~m}$, and static level between the water level in the storage reservoir and at the exit from the power house $h_{s}=180 \mathrm{~m}$. The initial surge chamber diameter is $D_{K}=4 \mathrm{~m}$ and it has to be selected in such a way to meet the stable-oscillation requirement $[18,19]$. Water level oscillations in surge chamber will be defined with regard to the reference plane set by water level in the storage reservoir. With regard to this plane, the connection between the surge chamber and the headrace tunnel is situated at $-10 \mathrm{~m}$. For the case of sudden start-up of the plant the analysis of oscillations must be made in order to check the hazard of air suction into the headrace tunnel.

It should be noted that computation results are influenced by the selection of time step, which is why the value of $\Delta t$ must be selected with due care [2]. In general, the accuracy of results increases with the reduction of time step $\Delta t$. However, this trend also involves reduction in computation efficiency, and 
so the problem of defining the time step $\Delta t$ is solved through compromise. Most frequently, the value of $\Delta t$ is defined as a percentage of the oscillation period $T$. In case of a cylindrical surge chamber, the oscillation period $T$ can be defined in advance [7], and so for the same case the value of $\Delta t$ is most often defined by the $T / m$ ratio, where $m$ is the parameter greater than 20 [2]. At that, as the oscillation period can not be defined in advance for surge chambers of general form, the same concept can be applied but with a higher value of $m$. Therefore, first the surge chamber of general form is approximated with a cylindrical surge chamber, and the value $T$ is defined, which is followed by definition of $\Delta t$ as the $T / m$ ratio. In this respect, several numerical analyses conducted for surge chambers of various forms have shown that $m>200$ provides results of appropriate accuracy. This principle was applied to define the value of $\Delta t$, which amounts to 0,59 s. Numerical examples presented below were prepared using the above presented numerical algorithm, which was for this purpose embedded in the computer package MathCAD 15 [20].

\subsection{Analysis of oscillations for the case $d Q_{s} / d t>0$}

The start-up of the hydropower plant will be defined by linear increase of the gate opening $\beta(20)$ from 0 , at the moment of $t=0$ $\mathrm{s}$, to the value of 1 at the moment of $t=120 \mathrm{~s}$. The surge chamber will be dimensioned by reducing the amplitude of oscillations by gradual widening of the bottom extension of the surge chamber. From the initial chamber diameter $D_{K}=4 \mathrm{~m}$ the bottom widening defined by the diameter $D_{d}$ will progressively be increased by the increment of $\Delta D_{d}=4 \mathrm{~m}$. The widening is trapezoidal in cross section, with the height of $3 \mathrm{~m}$ at the chamber periphery, and the height of $2 \mathrm{~m}$ at the other end. Measuring from the chamber and headrace tunnel interface, the horizontal axis of symmetry of the widening is situated at the height of $5.5 \mathrm{~m}$. The resulting time oscillations of water level in the surge chamber for the mentioned cases are presented in Figure 4.

It was established by the calculation that the bottom widening with the diameter $D_{d}=20 \mathrm{~m}$ (Figure 4.e) completely diminishes the oscillation amplitude, hence contributing to an undisturbed operation of turbines. On the contrary, in case the widening is assumed to be equal to the surge chamber diameter, $D_{d}=D_{k^{\prime}}$ this would result in the suction of air into the headrace tunnel and the penstock, as evidenced by the reduction in water level below the entrance to the surge chamber (Figure 4.a). It should be noted that the widening of the bottom part of the surge chamber also influences the oscillation period, as shown in Figure 4 by red line that connects neighbouring oscillation maximums and minimums. To define the influence of progressive increase in diameter $D_{d}$ on other flow parameters, the following is shown in Figure 5:
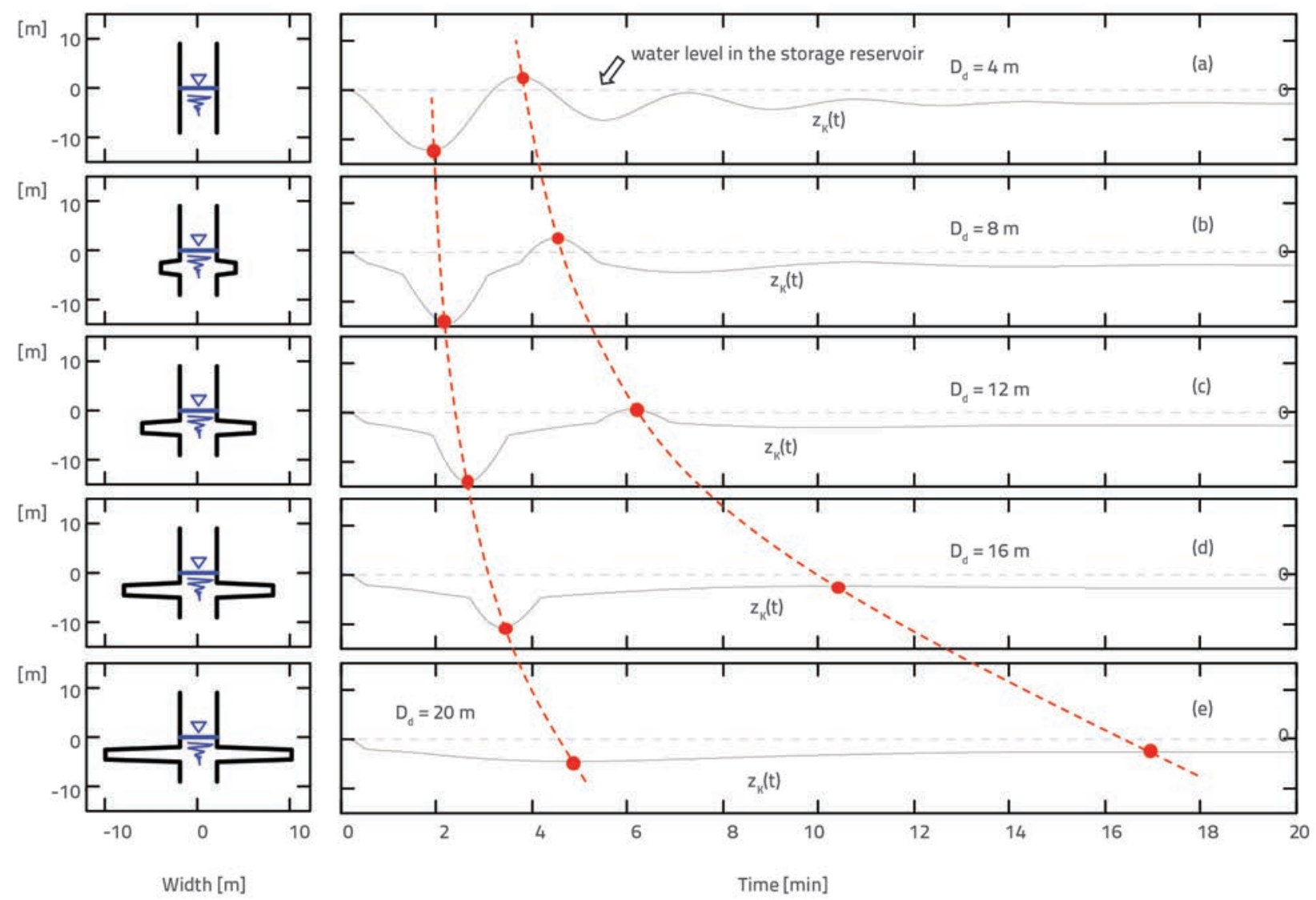

Figure 4. The dependence between oscillations $z_{k}(t) 0$ and the diameter of the bottom widening of the surge chamber is presented for the case of start-up of the hydropower plant 
a)

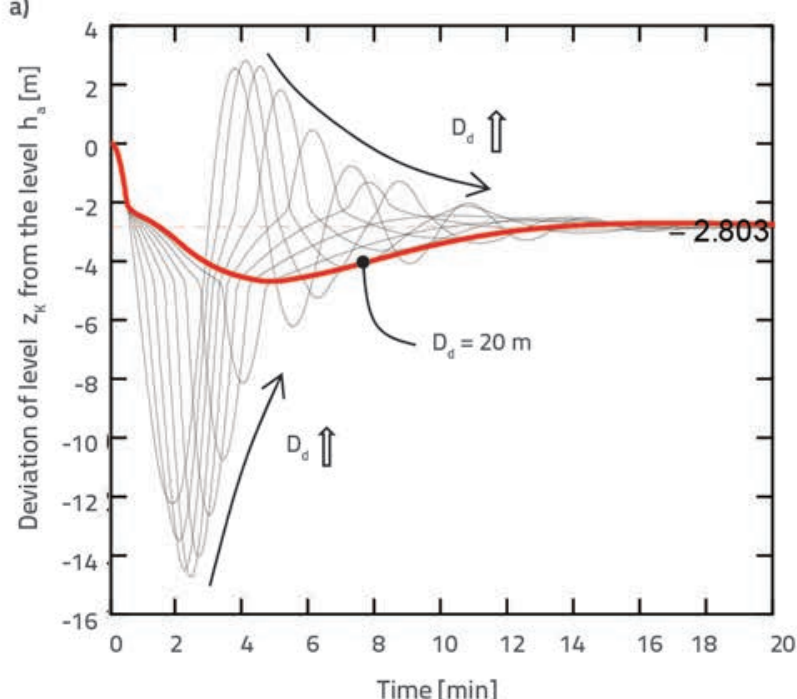

c)

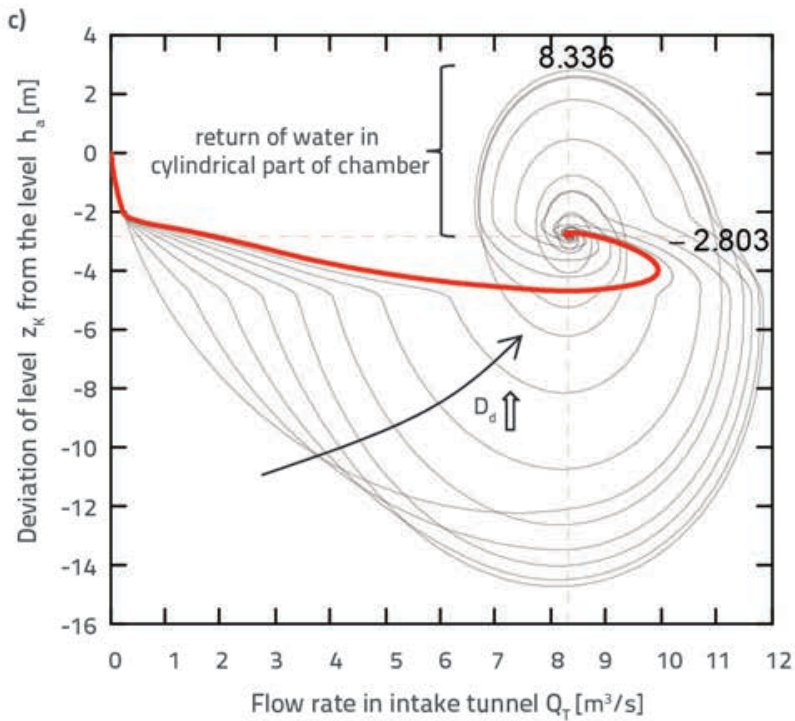

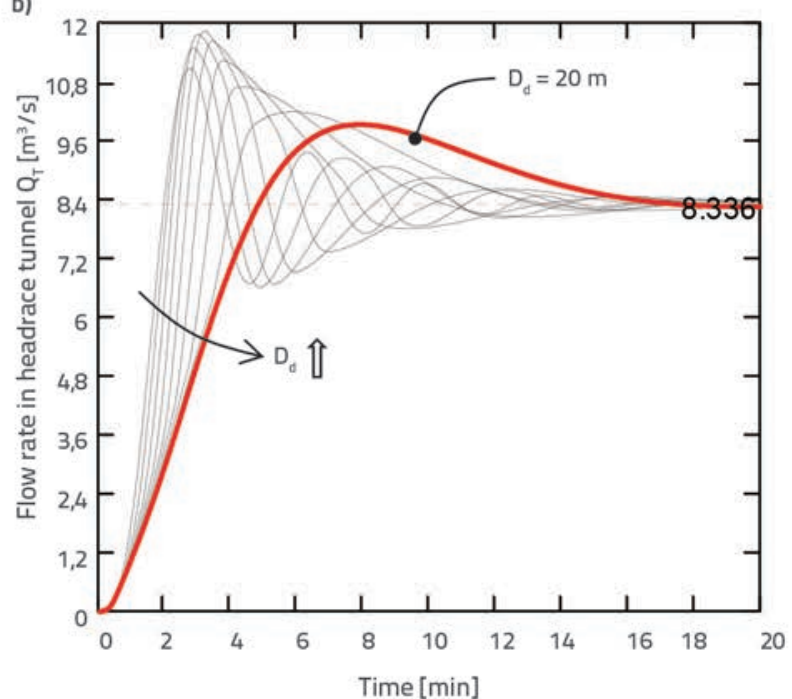

d)

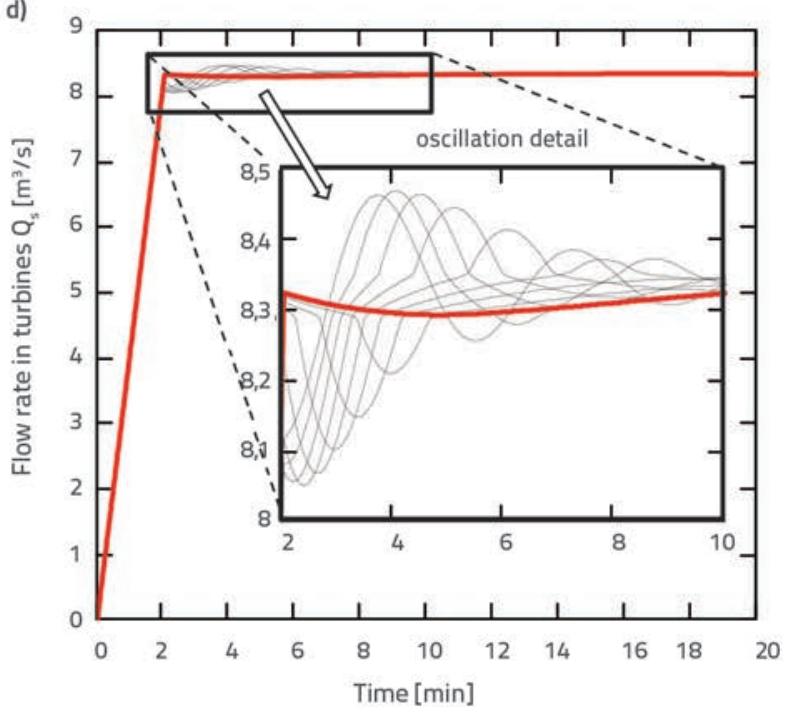

Figure 5. Parametric analysis results for the case of start-up of the hydropower plant. In diagrams, the red line points to results obtained for the maximum diameter $D_{d}$ of the bottom widening of the surge chamber $\left(D_{d}=20 \mathrm{~m}\right)$. The diagrams show: a) oscillations through which the level $z_{K}$ approaches the stationary value, b) oscillations through which the flow in headrace tunnel $Q_{T}$ approaches the stationary value, c) phase portrait of dissipative oscillations, and d) oscillations through which the flow $Q_{5}$ approaches the flow defined by the gate opening width

a) water level oscillation detail $z_{k 1}$ b) flow oscillation detail $Q_{T}$ in headrace tunnel, c) phase portrait of a dynamical system, and d) detail of flow oscillation $Q_{s}$ at turbines. Results obtained for the diameter $D_{d}=20 \mathrm{~m}$, which adequately reduces the oscillation amplitude, are marked with red line on all diagrams. The phase portrait, defined with coordinate axes $z_{K}$ and $Q_{p}$ points to the dynamics of transition to stationary state, which is equal for all cases, and is defined by the point in which the curves obtained for different diameters $D_{d}$ meet (Figure 5.c). In fact, the red line emphasises the case for the maximum tested value of the widening $D_{d}$ in which the stationarity point is achieved without greater deviations in the flow $Q_{T}$ and at the level $z_{K^{\prime}}$. Figure 5.d shows the change of flow $Q_{5}$ at turbines. Although the flow area $A_{s}$ at turbines is set by the time of change of the opening width $\beta$ (20), the flow rate at turbines will also be dependent on the change in water level at the surge chamber (21). This is why results of flow rate $Q_{S}$ are manifested in form of oscillations around values of stationary flow defined with the final gate opening width. This information can be used for analysing operation of flow regulator at turbines.

\subsection{Analysis of oscillations for the case $d Q_{s} / d t<0$}

The necessary width of the bottom widening of the surge chamber was established in the preceding example, and it 

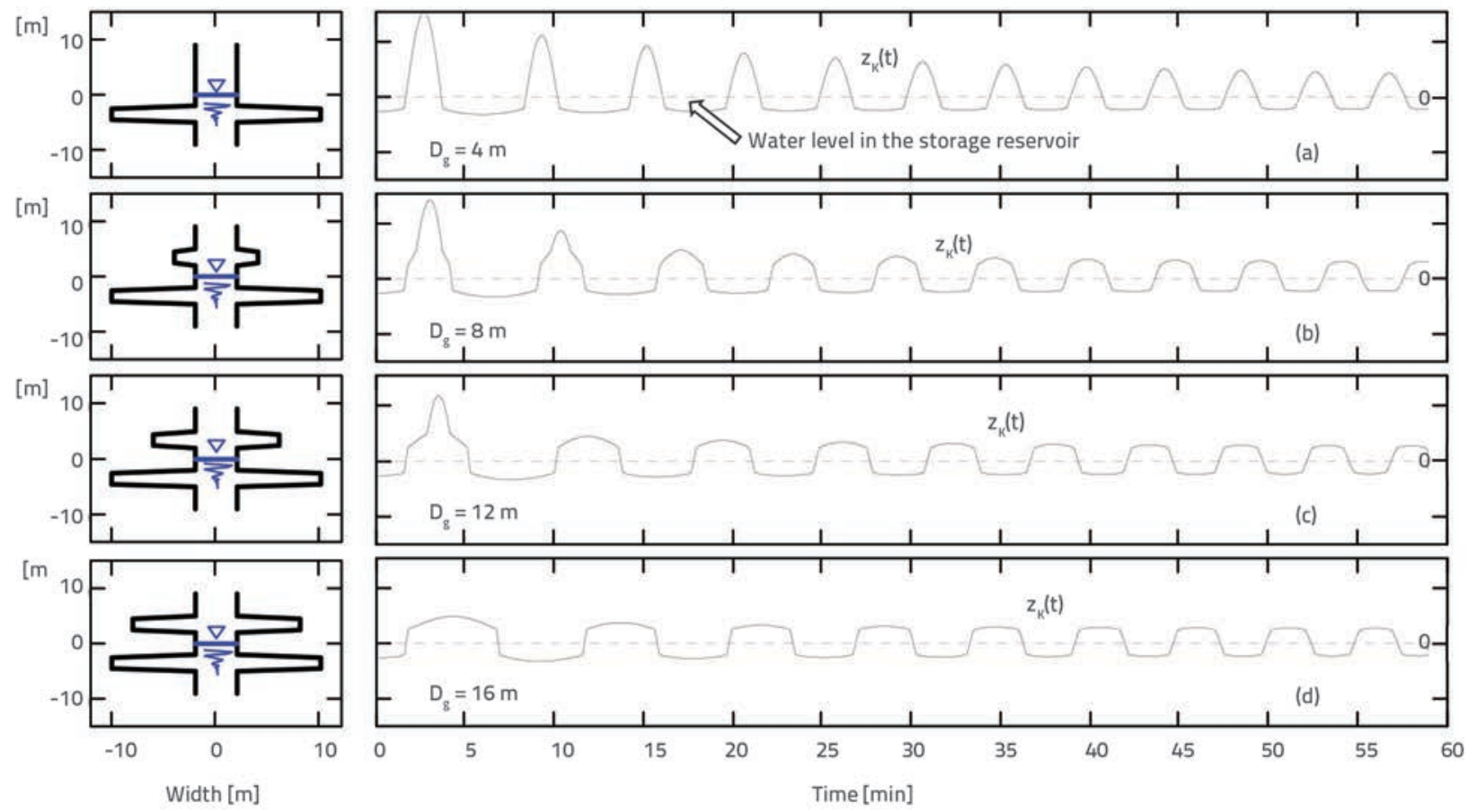

Figure 6. The dependence of oscillations $z_{k}(t)$ on the diameter of the top widening of the surge chamber is presented for the case of shut-down of the hydropower plant

was determined that the water level in surge chamber is $z_{K}=$ $-2.8 \mathrm{~m}$, and that the flow rate is $Q_{T}=8.33 \mathrm{~m}^{3} / \mathrm{s}$, which defines the stationary regime of operation of the hydropower plant (Figures 5.a and 5.b). The dimensioning of the top widening of the surge chamber, defined with the diameter $D_{g^{\prime}}$ will be conducted below for the case when the gate opening width $\beta$ linearly reduces from 1 in $t=0 \mathrm{~s}$ to the value of 0 in $t=$ $160 \mathrm{~s}$. Just like before, oscillations of water level in the surge chamber $z_{K}$ will be considered for the scenario of shut-down of the hydropower plant for different diameters of the top widening. Just like in the preceding case, the widening is trapezoidal in cross section, with one height amounting to 3 $\mathrm{m}$, and the other to $2 \mathrm{~m}$. Measuring from the water level in the storage reservoir, the cross sectional axis of symmetry of the widening is situated at the height of $3.5 \mathrm{~m}$. Starting from the value of $D_{g}=D_{k^{\prime}}$ the diameter of trapezoidal widening $D_{g}$ will progressively be increased with an increment of $\Delta D_{g}=$ $4 \mathrm{~m}$. At that, the initial geometry of the surge chamber will be defined by the last tested alternative from the preceding example (Figure 4e). Level oscillation results $z_{K}$ are presented in Figure 6.

Oscillation results for the initial surge-chamber geometry clearly show that the defined closing rate will result in the spilling of water from the chamber (Figure 6.a). However, by increasing the diameter $D_{g^{\prime}}$ a certain reduction in the maximum amplitude was established, as well as the influence of the change of the surge-chamber geometry (Figure 6.b) on the diagram $z_{k}(t)$. The influence of the change in geometry on the oscillation is even more pronounced in the following example (Figure 6.c). The diameter $D_{g}$ by which the water spilling was prevented is defined in the last example (Figure 6.d). In this case, it can also be observed how the defined surge-chamber geometry influences gradual reduction in the oscillation period.

Figure 7 shows results for other relevant values, obtained for the same range of tested diameters $D_{q^{\prime}}$ but with the double number of incremental increases $\left(\Delta D_{g}=2 \mathrm{~m}\right)$. The detail showing the water level oscillation $z_{k}$ over the period of $20 \mathrm{~min}$, in which the influence of the chamber geometry of the phasal displacement of oscillation can be observed, is given in Figure 7a. The detail showing oscillation of flow $Q_{T}$ in the headrace tunnel is presented in Figure 7b. Just like before (Figure 5c), the presented phase portrait of oscillations (Figure 7c) points to the time of approach to the no-operation state of the plant in which $z_{K}=0$ and $Q_{T}=0$. At that, the red line shows the change of $z_{K}$ and $Q_{T}$ values for the case of maximum diameter of $D_{g}$ and, in this case, a significant fall in the dumping influence can be observed, as evidenced by the decreasing distance between the neighbouring loops of the red curve which approaches the origin of the coordinate system. The fall in the influence of dissipative forces of friction can also be observed in Figure 7d in which the envelopes of maximum oscillation in the period of $60 \mathrm{~m}$ are presented.

\section{Conclusion}

The modelling of secondary water level oscillations in surge chambers of general form is presented in the paper for a typical high-pressure hydropower plant and for the defined change of flow rate in the power house. A method of incremental 
a)

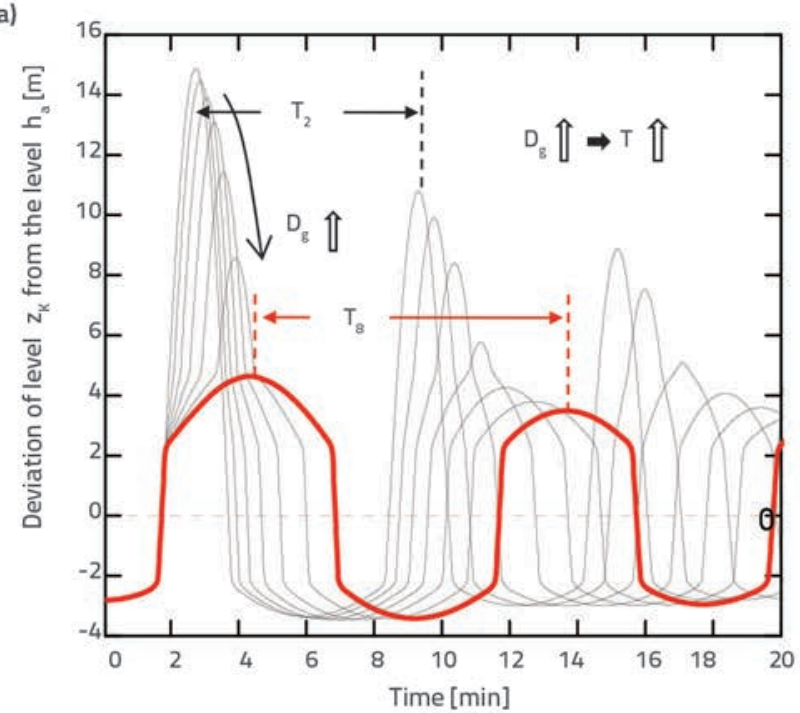

c)

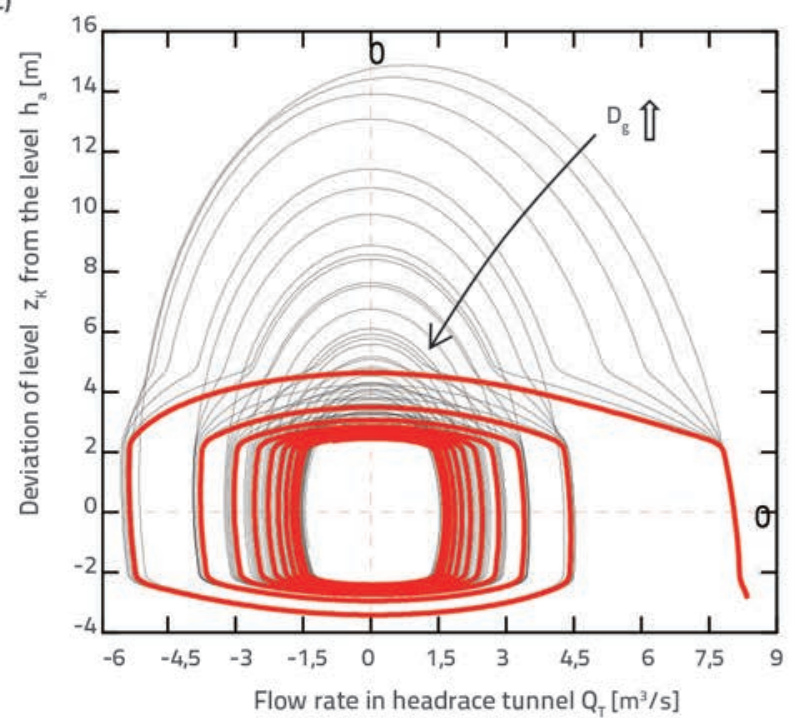

b)

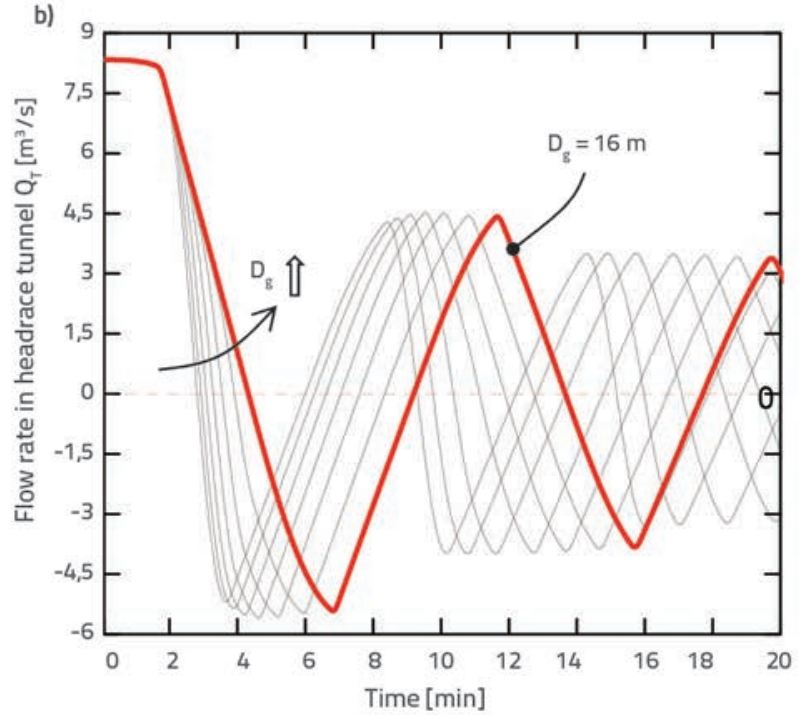

d)

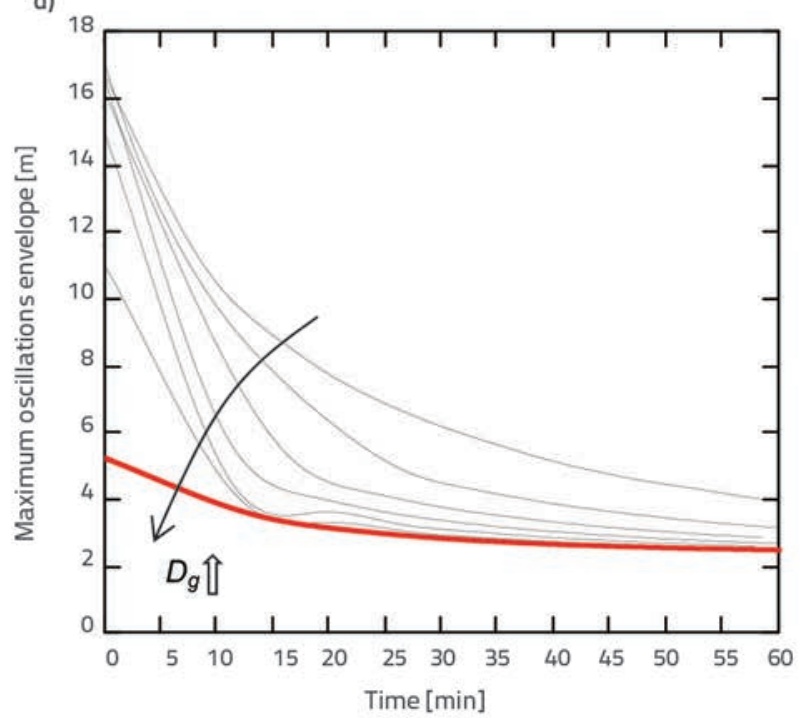

Figure 7. Parametric analysis results for the case of shut-down of the hydropower plant. The red line in diagrams points to the results obtained for the maximum diameter $D_{d}$ of the top widening of the surge chamber $\left(D_{g}=18 \mathrm{~m}\right)$. Diagrams show: a) oscillations through which the level $z_{K}$ approaches the water level in the storage reservoir $h_{A^{\prime}}$ b) oscillations through which the flow rate in the headrace tunnel $Q_{T}$ approaches the state defined by stationary state of water, c) phase portrait of dissipative oscillations, and d) envelope of maximum oscillations

integration of continuity equation has been developed for this purpose. The method is based on the idea of simulating the water entrance to or exit from the surge chamber with a series of fictitious time states. In this way, the volume of water $\Delta \mathrm{V}$ that either fills or empties the surge chamber in one time increment is divided into a finite number of equal segments $\Delta V_{K^{*}}$ Each volume segment $\Delta V_{K}$ is then introduced in the surge chamber or discharged from it, and the corresponding change in water level $\Delta z_{K}$ is calculated under assumption that the cross section of the surge chamber is constant. At that, the surgechamber cross section for the current volume segment $\Delta V_{K}$ is adopted as being equal to the cross section of the specified surge chamber, and this at the height at which the water level is currently situated. The progressive adding or reducing the volume $\Delta V_{k}$ is accompanied with progressive corrections of water level in the surge chamber. By defining water level in the surge chamber, the flow rate in the headrace tunnel is defined, with the presence of relevant local and linear losses, through dynamic equation discretisation using the finite difference method. In order to create numerical applications, the resulting numerical algorithm is implemented in the program package MathCAD 15. Numerical examples were realized in such a way to present the dimensioning procedure for the gallery-type surge chamber, and they include cases of water level oscillations occurring after start-up and turn-off of the hydropower plant. Other than the obvious simplicity evidenced through computer implementation of the method, and unlike the direct integration, this method offers the possibility of considering oscillations in surge chambers of general form, but also in surge chambers of high complexity. 


\section{REFERENCES}

[1] Amara, L., Berreksi, A. \& Abdoune, K.: Computation of mass oscillations in a surge tank by finite element technique, Larhyss Journal, ISSN 1112-3680, n¹5, pp. 139-149, 2013.

[2] Ivetić, M.V.: Računska hidraulika - Tečenje u cevima, Gradjevinski fakultet Univerziteta u Beogradu, 1995.

[3] Agroskin, I.I., Dimitrijev, G.T. \& Pikalov, F.I.: Hidraulika, Tehnička knjiga, Zagreb, 1973.

[4] Raus, H.: Tehnička hidraulika, Građevinska knjiga, Beograd, 1969.

[5] Jaeger, C.: A review of surge tank stability criteria, Annual Meeting of The A.S.M.E., 1959., doi:10.1115/1.3662744

[6] Wei, J.P: Influence of large oscillations on stability of simple surge tank, Master Thesis of Applied Science in the Department of Civil Engineering, University of British Columbia, 1963.

[7] Moghaddam, M.A.: Analysis and design of a simple surge tank, IJE Transactions A: Basics, Vol. 17, No. 4, pp. 339 -345, 2004.

[8] Calamak, M., Bozkus, Z.: Numerical investigation of operation levels in a surge tank of small hydropower plant, 10th International Congress on advances in civil engineering, Ankara, 2012.

[9] Bergant, A. \& Simpson, A.R.: Development of a generalised set of pipeline water hammer and column separation equations, Research Report No. R149, University of Adelaide, Dept. of civil and environmental engineering, 1997.

[10] Brunone, B., Golia, U. \& Greco, M.: Some remarks on the momentum equation for fast transients, Int. Meeting on hydraulic transients with column separation, 9th and last round table of the IAHR Group, 1992.
[11] Bartolić, I., Berbić, J. \& Gjetvaj, G.: Hidraulička dioda kao asimetrični prigušivač, Hrvatske vode 21 (85), pp. 235-242, 2013.

[12] Chaudhry, M.H.: Applied hydraulic transients, Second ed. Van Nostrand Reinhold Co., New York, N.Y., 1987.

[13] Wylie, E.B. \& Streeter, V.L.: Fluid trainsients in systems, Prentice-Hall, Englewood Cliffs, New Jersey, 1993.

[14] Colebrook, C.F.: Turbulent flows in pipes with particular reference to the transition region between smooth and rough pipe laws, J. Inst. Civil Engng., London, 1939.

[15] Haaland, S.: Simple and explicit formulas for the friction factor in turbulent flow, J. Fluids Engng.105, pp. 89-90, 1983., doi:10.1115/1.3240948

[16] Moghaddam, M.A.: Numerical investigation on transient incompressible fluid flow, 5th WSEAS Int. Conf. on Fluid Mechanics (FLUIDS'08) Acapulco, Mexico, pp. 25-27, 2008.

[17] Daily, W., Hankey, W. Olive, R. \& Jordan, J.: Resistance coefficients for accelerated and decelerated flows through smooth tubes and orifices, Transactions of ASME, pp. 1071-1077, 1956.

[18] Nabi, G., Rehman, H., Kashif, M. \& Tariq, M.: Hydraulic transient analysis of surge tanks: Case study of Satpara and Golen Gol Hydropower projects in Pakistan, Pak. J. Engg. \& Appl. Sci., Vol. 8, pp. 34-48, 2011

[19] Thoma, D.: Zur Theorie des wasserschlosses bei selbsttaetig geregelten turbinenanlagen, Oldenburg, Munchen, Germany, 1910.

[20] Mathsoft, Mathcad Plus 5.0 - User's guide. Mathsoft Inc., Cambridge, MA, 1993. 